Quim. Nova, Vol. 34, No. 5, 910-916, 2011

\title{
ROADMAP TECNOLÓGICO EM MATÉRIAS-PRIMAS RENOVÁVEIS: UMA BASE PARA A CONSTRUÇÃO DE POLÍTICAS E ESTRATÉGIAS NO BRASIL
}

\author{
Paulo Coutinho \\ IDEOM/BRASKEM, Av. das Nações Unidas, 8501, 24º andar, 05425-070 São Paulo - SP, Brasil \\ José Vitor Bomtempo*
}

Escola de Química, Universidade Federal do Rio de Janeiro, Av. Horácio Macedo, 2030, B1. E, Ilha do Fundão, 21941-909

Rio de Janeiro - RJ, Brasil

Recebido em 19/4/10; aceito em 3/11/10; publicado na web em 25/2/11

\begin{abstract}
A TECHNOLOGY ROADMAP IN RENEWABLE RAW MATERIALS: A BASIS FOR PUBLIC POLICY AND STRATEGIES IN BRAZIL. This paper presents a technology roadmap applied to renewable raw materials as a basis for public policy and strategies in Brazil. The roadmap, developed by Braskem professionals and academic experts, intends to be a basis of discussion and common language creation regarding the possible utilization of renewable raw materials for biofuel and chemical production in Brazil. Following this perspective, the roadmap is presented to public debate and contribution from the stakeholders. The paper describes the roadmap construction and presents the main implications for policy and strategy goals. An analysis of the innovation dynamics in renewable raw materials is developed as an outcome of the roadmap.
\end{abstract}

Keywords: technology roadmaps; biofuels; bioproducts.

\section{INTRODUÇÃO}

A preocupação com as mudanças climáticas e as medidas que vêm sendo adotadas no mundo para seu controle deverão ter impacto direto na atividade industrial. Essa perspectiva tem levado ao crescimento de investimento em tecnologias e produtos mais "limpos". Na área de energia em particular, somam-se ainda para muitos países questões estratégicas ligadas à segurança de abastecimento e busca de níveis menos desconfortáveis de dependência. Nesse contexto, abrem-se oportunidades para o desenvolvimento de uma indústria baseada em matérias-primas renováveis (MPR). Além dos biocombustíveis já conhecidos, um fluxo de inovações em desenvolvimento pode estar lançando as bases de uma indústria integrada de exploração da biomassa. Essa indústria pode ultrapassar os limites da produção de biocombustíveis e oferecer rotas para a substituição de matériasprimas fósseis e introdução de novos produtos químicos. No futuro, quando a base de matérias-primas deixar de ser fóssil, energia e química serão certamente indústrias muito diferentes das atuais.

O Brasil tem uma posição interessante nesse cenário. O país é líder na utilização de matérias-primas renováveis para fins energéticos - a indústria do etanol é a referência mundial no setor. A petroquímica, construída nas últimas quatro décadas com base em tecnologias externas, consolidou-se recentemente em empresas de porte internacional. À primeira vista, parecem existir vantagens comparativas para a participação brasileira na indústria do futuro baseada em MPR. Entretanto, essa indústria, ainda em construção, pode exigir um esforço tecnológico considerável. Como se caracteriza a dinâmica tecnológica dos desenvolvimentos em curso no mundo? Que políticas e estratégias de inovação podem preparar o país para disputar uma posição de destaque nessa área? Em que medida a atual vantagem competitiva em etanol pode ser mantida ao longo do tempo? Ou melhor, em que medida a vantagem competitiva em etanol pode

*e-mail: vitor@eq.ufrj.br ser transferida para a indústria do futuro baseada em MPR e levar o país a ter uma posição proativa nessa indústria?

Essas questões trazem à tona um problema central: como realizar um planejamento tecnológico que possa servir de base para as políticas e estratégias de ciência, tecnologia e inovação adequadas à indústria do futuro? Diversos exercícios de planejamento têm sido usados para orientar a reflexão e a elaboração de estratégias em novas tecnologias. A construção de Technology Roadmaps é uma dessas ferramentas. ${ }^{1,2}$ Ao conectar mercados, produtos e tecnologias em relação ao tempo, essa ferramenta fornece um modo de identificar, avaliar e selecionar alternativas tecnológicas que podem ser usadas para responder aos problemas do presente e do futuro. ${ }^{3-7}$ A contribuição dos roadmaps às organizações, sejam elas empresas ou organismos governamentais, se dá principalmente pela orientação que propiciam ao monitoramento do ambiente e à avaliação e acompanhamento de tecnologias específicas. Incluem-se aqui as tecnologias de ruptura, ${ }^{8}$ que podem ter o potencial de redefinir uma indústria ou eventualmente de criar uma indústria inteiramente nova. Os roadmaps de tecnologias de ruptura ${ }^{9}$ podem ser particularmente úteis no cenário atual das indústrias química e de energia.

Nessa linha de pensamento, a Braskem realizou durante o ano de 2009 um processo de reflexão que congregou, ao lado dos departamentos da empresa, a universidade e instituições de pesquisa. Esse processo envolveu a elaboração de estudos, a realização de reuniões conjuntas e outras atividades interativas envolvendo as diversas instâncias mobilizadas. Um dos resultados foi a elaboração de um roadmap tecnológico para as MPR com base em metodologia própria adaptada das principais referências da literatura. ${ }^{5-7,10} \mathrm{O}$ roadmap não representa a estratégia da Braskem mas, antes de tudo, pretende ser um documento de partida para discussão, a ser submetido aos diversos grupos de interesse envolvidos no futuro da tecnologia e da inovação no Brasil.

Este artigo apresenta o roadmap Matérias-Primas Renováveis (rMPR) desenvolvido sob a coordenação da Braskem e discute as 
suas implicações tanto para as políticas científicas e tecnológicas quanto para as estratégias das empresas brasileiras interessadas em explorar oportunidades em MPR. O interesse principal deste trabalho é, portanto, a apresentação de um ponto de partida estruturado, de modo a facilitar a discussão sobre a posição estratégica que o país pretende ocupar no cenário futuro da indústria baseada em MPR. Esse ponto chama a atenção para o potencial brasileiro e, ao mesmo tempo, para os desafios envolvidos na mudança de base de matériaprima na indústria química e a construção de vantagens competitivas no paradigma pós-petróleo.

O artigo está organizado em três seções, além desta introdução. Em seguida, o rMPR é apresentado e são destacados os resultados obtidos em termos de mercados, tecnologias e produtos identificados. Apresenta-se, a seguir, com base nas informações organizadas no rMPR, uma discussão dos pontos centrais que caracterizam a dinâmica da inovação em MPR. Na última seção, as considerações finais complementam a discussão, sublinhando as implicações do rMPR para a formulação de políticas e estratégias em MPR no Brasil, e apresentam as conclusões do artigo.

\section{APRESENTAÇÃO DO ROADMAP DE MATÉRIAS-PRIMAS RENOVÁVEIS (RMPR)}

O rMPR foi desenvolvido conforme metodologia própria. Por meio de discussões internas foram levantados os drivers, ou elementos direcionadores do mercado para a indústria baseada em MPR. A partir daí, iniciou-se o exercício de prospecção tecnológica. Esse exercício contou com a contribuição de um grupo da universidade com experiência em prospecção tecnológica e, também, com visão abrangente das indústrias de energia e química. O objetivo foi identificar os produtos e tecnologias relacionados às MPR que, nos horizontes de 5,10 e 15 anos, poderiam vir a ser desenvolvidos. A identificação dos produtos e tecnologias partiu do documento elaborado pela universidade e foi complementada em discussões internas e em interação com o próprio grupo. As informações consolidadas nesse processo foram passadas à área de Inovação Tecnológica Corporativa da Braskem, que construiu então a primeira versão do rMPR.

As Figuras 1, 2 e 3 apresentam o rMPR. Descreve-se, em seguida, o conteúdo das principais informações utilizadas na sua construção.

O ponto de partida para a construção do rMPR é a identificação dos drivers que contribuem para a utilização crescente de MPR. Esses drivers representam os fatores de mercado e de sociedade que devem impulsionar e orientar o ritmo de introdução dos produtos e processos. São descritas as evoluções das tecnologias, o que permite a identificação de produtos e a análise de projetos importantes em andamento na utilização de MPR.

Diversos fatores podem ser vistos como determinantes do interesse crescente pelas MPR, entre os quais os de maior peso são: o potencial da biologia industrial ou white biotechnology, as restrições ambientais ao uso de matérias-primas fósseis, ${ }^{11}$ a orientação das estratégias empresariais ${ }^{12}$ e a perspectiva da inovação tecnológica como saída de crise. ${ }^{13}$

\section{Evolução dos mercados}

\section{Crescimento esperado dos biocombustíveis}

Os biocombustíveis hoje comercializados são o bioetanol e o biodiesel. O bioetanol é produzido, atualmente, por fermentação a partir de biomassa que contenha quantidades significativas de amido (milho, trigo e outros cereais) ou açúcares (cana, beterraba).

Projeta-se um crescimento da ordem $14 \%$ a.a. para os biocombustíveis líquidos nos próximos 5 anos, sendo o mercado atual da ordem de US\$ 26 bi. ${ }^{14}$ Para o mercado americano em particular, existe uma previsão de incorporação de biocombustíveis avançados que corresponde a uma taxa anual média de crescimento da ordem de $10 \%$ para os próximos 20 anos. ${ }^{15}$

\section{Crescimento esperado de bioprodutos e biopolímeros}

De maior interesse para a identificação dos mercados futuros da chamada white biotech são os produtos químicos por fermentação e por processos enzimáticos. Esses dois grupos representam hoje um mercado estimado em US\$ 15 bi. Incluem-se aqui a introdução e o crescimento de novos biopolímeros e de produtos químicos convencionais a partir de rotas biológicas. Estima-se um potencial de crescimento anual de $8 \% .^{14}$

Os biopolímeros incluem os polímeros extraídos diretamente da biomassa (ex: derivados da celulose e do amido), produzidos diretamente de micro-organismos no seu estado natural ou modificados geneticamente (ex.: PHA, PHB), novos polímeros obtidos a partir de biointermediários (PLA, Green PET), plásticos biodegradáveis obtidos por aditivação de plásticos convencionais (Ecoflex, poliéster biodegradável da BASF) e plásticos convencionais produzidos a partir de MPR (biopolietileno).

Uma questão importante no crescimento relativo desses biopolímeros será a definição da qualidade ambiental desses produtos que venha a se estabelecer na sociedade. Se a definição se der com base na carga de gases de efeito estufa gerados, o espaço de biopolímeros convencionais a partir de fontes renováveis sustentáveis (ex: polietileno a partir de etanol de cana) pode crescer de forma significativa. Se, entretanto, prevalecer uma visão de contestação da utilização de plásticos pela visibilidade da poluição gerada, o segmento pode favorecer os ditos biodegradáveis, em particular os produtos como o PLA.

As estimativas do mercado atual de biopolímeros são, em razão das diferentes definições adotadas, bastante discrepantes. De modo geral, o mercado europeu encontra-se bem mais desenvolvido do que o americano. Destaque-se em particular o potencial de crescimento dos biopolímeros. No período 2003 a 2007 a capacidade de produção cresceu na faixa de $40 \%$ ao ano e o potencial técnico de substituição de plásticos petroquímicos por bioplásticos é estimado em $90 \% .{ }^{16}$ Destaquem-se as elevadas taxas de crescimento dos bioplásticos biodegradáveis, como PLA e outros, que são atualmente da ordem de $17 \%$ ao ano. ${ }^{16}$

O potencial de crescimento dos bioplásticos é ainda refletido na evolução do mercado de embalagens. O segmento dito de embalagens sustentáveis tem crescimento esperado para os próximos anos na faixa de $25 \%$ a.a.

\section{Evolução das tecnologias}

Algumas tecnologias chave devem ser desenvolvidas e ultrapassar o presente estágio de piloto ou demonstração para que a utilização de biomassa para a produção de biocombustíveis e bioprodutos possa se tornar presente de fato. Na conversão da biomassa destacam-se duas rotas: bioquímica e termoquímica. Essas duas rotas podem ser vistas como em competição, não sendo claro no estágio atual se uma delas virá a dominar o mercado ou se ambas se desenvolverão de forma complementar.

Além do desenvolvimento das tecnologias de conversão, existem ainda desafios a serem superados nas tecnologias de suporte, principalmente no pré-tratamento das matérias-primas e na separação dos produtos de conversão (pós-tratamento). Restaria, finalmente, a integração dos processos numa unidade comercial otimizada segundo os princípios da engenharia química.

\section{Rota bioquímica}

Os principais projetos em desenvolvimento pela rota bioquímica estão voltados para a produção de etanol a partir de materiais ligno- 
celulósicos. Existem diversas unidades piloto em operação e algumas unidades de demonstração. As unidades em escala comercial ainda estão em construção ou, na maioria dos casos, apenas como projetos anunciados.

A rota de conversão bioquímica possui duas etapas. A primeira está relacionada à quebra do material lignocelulósico em moléculas fermentáveis. Na segunda etapa, essas moléculas são convertidas no produto desejado por fermentação, usando micro-organismos modificados ou não geneticamente. A primeira etapa foi alvo de um esforço específico do DOE que financiou pesquisas com metas de redução do custo da celulase. No final dos anos 1990, Genencor e Novozymes receberam, cada uma, cerca de US\$ 15 milhões para reduzir em 10 vezes o custo das enzimas. Os objetivos foram atingidos e o custo da celulase ficou abaixo de $50 \notin$. Atualmente encontra-se entre $20 \mathrm{e}$ $50 \phi$ gal de etanol, sendo necessária ainda uma redução a 3 a $4 \phi$ gal para atingir a paridade com o etanol de milho americano. ${ }^{17}$ Ressaltese que o salto realizado em relação aos valores dos anos 90 reduziu o custo de produção de etanol celulósico de uma faixa superior a $6 \mathrm{US} \$ / \mathrm{L}$ para pouco menos de 1,5 US $\$ / \mathrm{L}$ em 2005. Isso sugere o enorme potencial dos processos enzimáticos a partir de biomassa, considerando-se que existe ainda potencial de redução de custos na matéria-prima e logística de suprimento, no pré-tratamento e na integração dos subprocessos.

Citam-se ainda trabalhos de melhoramento genético de microorganismos e o uso de novos micro-organismos visando ao aumento de produtividade e/ou geração de novos bioprodutos. São processos capazes de melhorar os processos de produção de etanol (transformação de celulose a etanol em única etapa) ou de gerar novos produtos como alcoóis com maior número de átomos de carbono (ex: butanol e outros) ou outros produtos (ex: isoprenoides a partir da cana-deaçúcar que têm características de diesel).

Cabem aqui comentários a respeito do uso de algas para captura de $\mathrm{CO}_{2}$ e produção de biomassa, bio-óleo e produtos de alto valor agregado (espirulina, astaxantina, carotenos, etc.). Apesar do grande interesse que a utilização de algas para a produção de biocombustíveis e bioprodutos tem despertado, os problemas existentes são vistos ainda como importantes. O potencial é reconhecido: alto rendimento em óleo $(60 \%)$, rápido crescimento, utilização de terras e recursos de baixo custo de oportunidade, não competição com alimentos e captura e uso de $\mathrm{CO}_{2}$. Por isso, os investimentos têm sido expressivos. Entretanto, ainda é necessária melhor compreensão dos princípios de base para que o scale-up comercial seja viável. Considerações tanto de biologia quanto de engenharia são críticas e $P \& D$ fundamental e aplicado ainda parece necessário. ${ }^{18}$

\section{Rotas termoquímicas: gaseificação/pirólise/reforma}

A rota termoquímica está sendo abordada segundo 3 diferentes linhas: gaseificação, pirólise e "reforma catalítica". A gaseificação da biomassa, a exemplo da gaseificação já conhecida de carvão e gás natural, visa a produção de gás de síntese e posterior conversão, em geral via reação de Fischer Tropsch (FT), em combustíveis líquidos (diesel, nafta, querosene) ou produtos químicos e outros energéticos (DME, metanol e outros). A pirólise visa a produção de um bio-óleo a partir da exposição rápida da biomassa a elevadas temperaturas. O bioóleo é estabilizado e, em seguida, encaminhado para processamento nas refinarias de petróleo. A pirólise pode ainda resolver o problema de logística relacionado ao transporte da biomassa. A reforma utiliza processos catalíticos - portanto, não necessariamente térmicos também para a obtenção de bio-óleo. Nesse caso, diferentemente da pirólise, o processo já elimina o oxigênio existente na biomassa, não requerendo processamento posterior, o que facilita o encaminhamento para as unidades de refino existentes. Tanto a pirólise quanto a reforma catalítica podem gerar o que costuma ser chamado de "nafta verde".
São citadas como vantagens da rota termoquímica: a flexibilidade na utilização de diferentes tipos de matérias-primas, como resíduos diversos e lixo; a obtenção de combustíveis semelhantes aos derivados do petróleo; a experiência acumulada em gaseificação de carvão e outros fósseis; a flexibilidade do gás de síntese para produção de combustíveis e químicos e a possibilidade de integração com as unidades de refino existentes.

No caso da gaseificação, registre-se que algumas alternativas em desenvolvimento buscam uma solução para os inconvenientes da gaseificação tradicional. É o caso principalmente da gaseificação por plasma, cuja grande vantagem seria a produção de um gás de síntese limpo a partir de qualquer tipo de matéria-prima. Existem algumas plantas piloto em operação, mas problemas de engenharia ainda têm que ser resolvidos para tornar esta tecnologia viável.

\section{Integração dos subprocessos, investimentos, custos e escalas das biorrefinarias}

A obtenção de etanol de materiais lignocelulósicos pela via bioquímica contempla 8 subprocessos que devem ser desenvolvidos e integrados: pré-tratamento, fracionamento, produção de enzimas, hidrólise enzimática, fermentação das pentoses e hexoses, recuperação do etanol, recuperação da lignina e sua utilização e tratamento dos resíduos. ${ }^{19}$ Outros processos de conversão pela rota bioquímica devem considerar o uso de um ou mais desses subprocessos. Ocorre que alguns deles devem ser ainda desenvolvidos para atingir o estágio comercial, o que representa uma barreira importante para a concepção de projetos com custos de investimento e de operação dentro das faixas ideais.

As estimativas do custo do investimento para produção de etanol celulósico são muito variadas e dependem da matéria-prima e do tipo de pré-tratamento. Segundo IEA Bioenergy ${ }^{19}$ os valores atuais oscilam entre US\$ 0,88/L e US\$1,20/L de capacidade, dependendo do tipo de pré-tratamento e da escala de produção considerada. Nas condições "ideais", o custo de investimento deveria ser da ordem de US\$ 0,66/L para uma escala de 245 milhões de litros de etanol/ano.

A meta de custo para o etanol celulósico americano, indicada pelo DOE, é de atingir em 2012 um custo de produção de cerca de 0,28 US $\$ /$ L. Essa meta parece de difícil alcance, segundo IEA Bioenergy. ${ }^{19}$

$\mathrm{Na}$ busca de redução de custos, uma trajetória clássica na indústria química é a de aumento das escalas das plantas. A busca de uma trajetória de ganhos de escala está claramente explicitada no planejamento tecnológico americano. Almeja-se que as escalas médias se tornem cinco vezes maiores entre 2010 e 2030, o que vai exigir um considerável esforço de engenharia. ${ }^{15} \mathrm{O}$ investimento nas biorrefinarias é capital intensivo. Estima-se que o investimento para uma biorrefinaria processando $4.000 \mathrm{t} / \mathrm{d}$ de milho $(2.000 \mathrm{t}$ de grão e $2.000 \mathrm{t}$ de forragem) seja atualmente da ordem de US\$ 450 milhões. ${ }^{20}$

\section{Produtos}

Os produtos com potencial de produção são, a seguir, apresentados nos horizontes de curto (2010-2014), médio (2014-2019) e longo prazo (após 2019). No curto prazo (Figura 1), encontram-se os produtos já com anúncio de produção comercial pelas empresas.

As patentes depositadas nos últimos 5 anos definem os produtos com produção potencial em médio prazo, entre 2014 e 2019 (Figura 2 a e b). Por fim, os produtos em estudos em universidades e centros de pesquisa foram identificados a partir da literatura científica e considerados em longo prazo (Figura 3) para depois de 2019. As discussões nos workshops de elaboração do rMPR levaram a alguns ajustes pontuais nos critérios acima. 


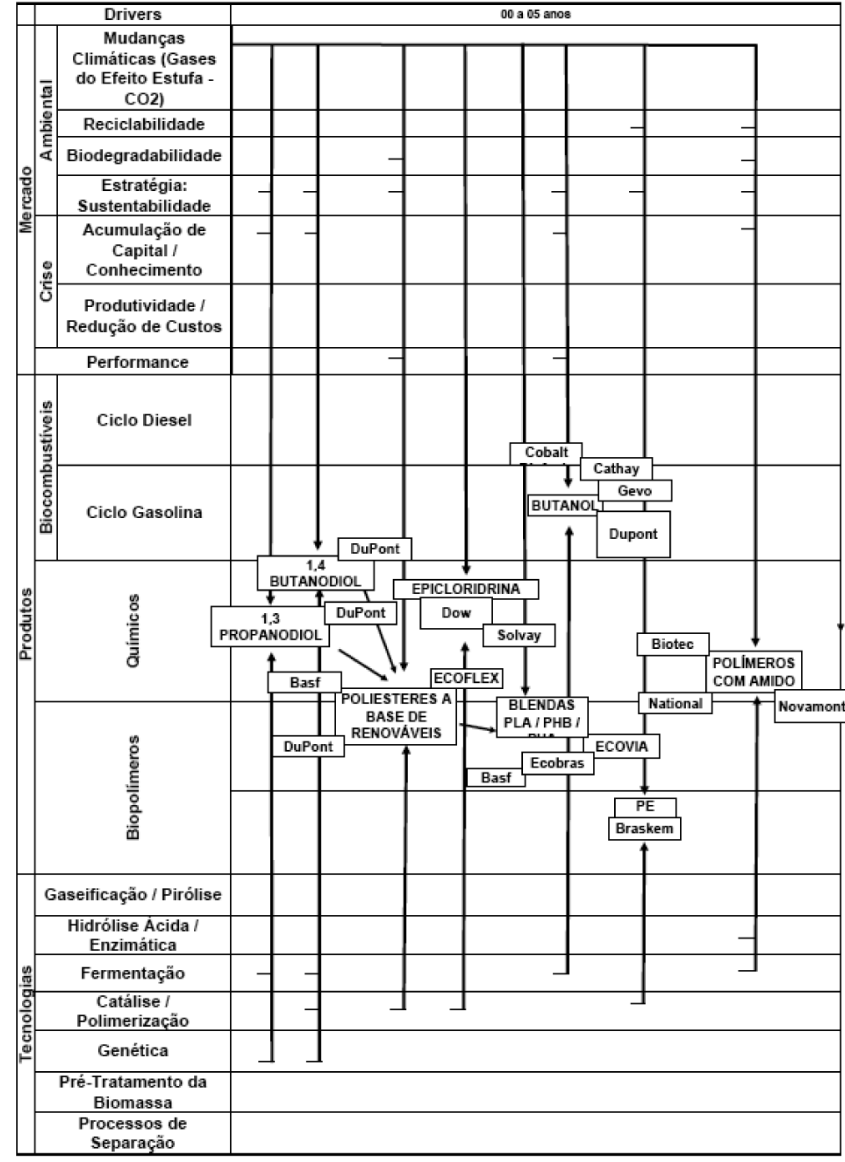

Figura 1. Roadmap tecnológico de matérias-primas renováveis - curto prazo

\section{Período 2010-2014}

No período, devem ser consolidados os investimentos na área. Os poliésteres da Du Pont, que utilizam propanodiol e butanodiol de fontes renováveis, deverão ganhar mercado. As boas características do butanol, como combustível e como intermediário químico, têm trazido alguma atenção para o desenvolvimento de processos de produção do biobutanol. Alguns projetos estão em andamento, destacando-se o da Butamax (Du Pont/BP) e o da Gevo. Considera-se a possibilidade de produção comercial em curto prazo. As apostas da Du Pont no biobutanol têm sido respaldadas por uma base de patentes, sendo 12 nos 2 últimos anos. Citam-se ainda outras iniciativas para a produção de biobutanol: Cathay (China) e Usina Paraíso (Brasil) a partir de açúcares, Cobalt Biofuels (EUA) e Green Biologics (Reino Unido), que utilizam a biotecnologia moderna em seus processos. Uma estratégia que pode facilitar o desenvolvimento da produção é a adaptação de unidades de produção de etanol, o que reduz consideravelemente o custo do investimento.

BASF deve aumentar os investimentos na comercialização de seus plásticos biodegradáveis e compostáveis. A empresa tem trabalhado com blendas biodegradáveis, combinando biopolímeros com polímeros convencionais para obter as propriedades desejadas. BASF tende a incorporar MPR em seus processos. Solvay e Dow estão anunciando plantas para produção de epicloridrina a partir de glicerina. Braskem deverá iniciar ainda em 2010 a produção de biopolietileno a partir de etanol. Dow tem projeto semelhante.

Um produto com perspectivas de crescimento expressivo no período é o PLA. As dificuldades para maior difusão desse plástico estão em limitações nas propriedades e o alto custo de produção. $\mathrm{O}$ produto concorre principalmente com o PET e o poliestireno. Natureworks (Cargill) é a principal produtora. Teijin e Purac estão também

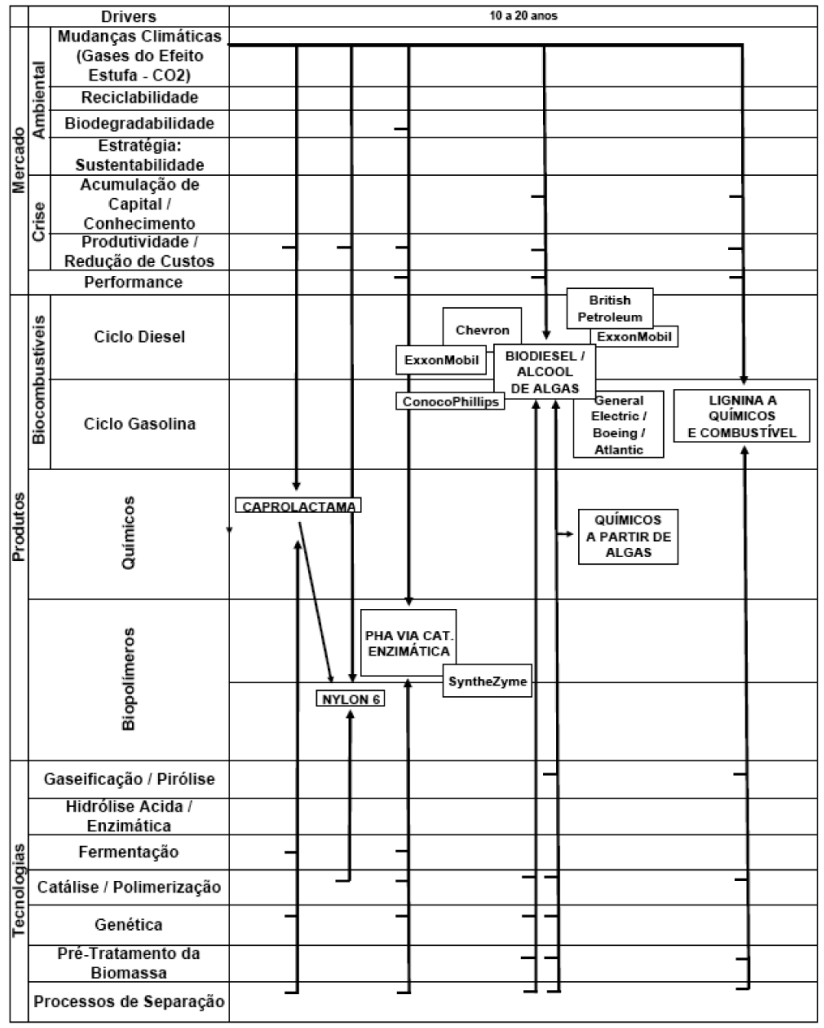

A

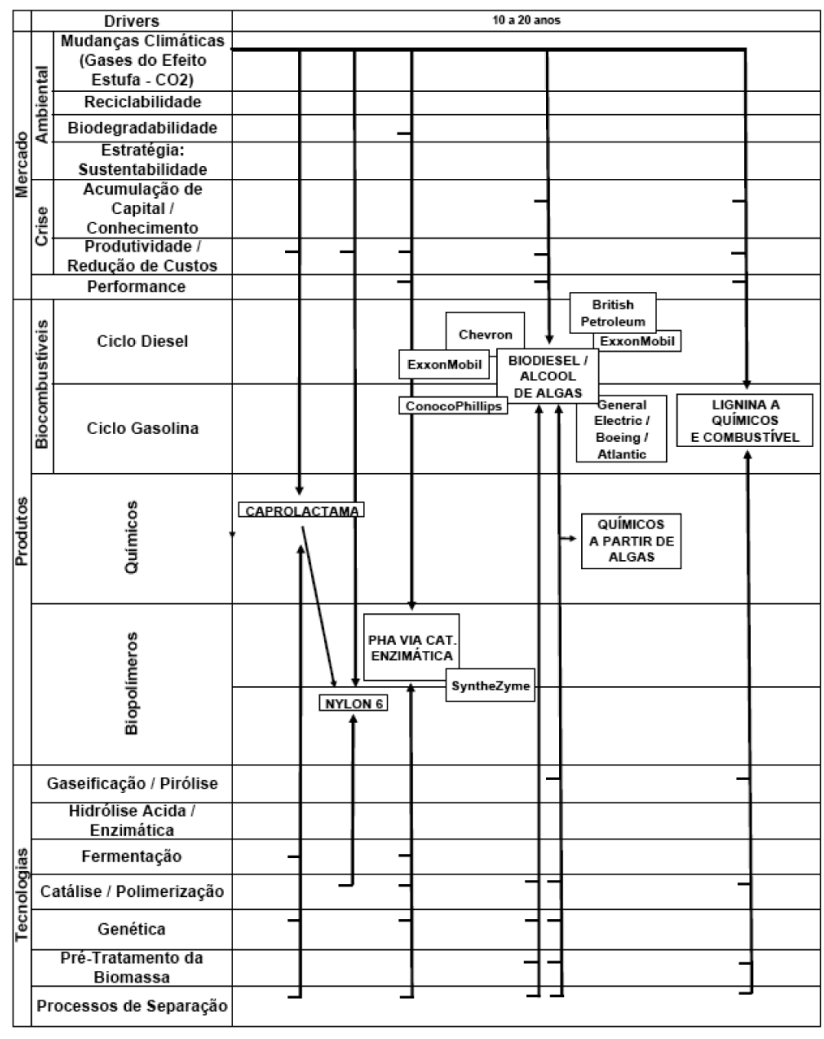

B

Figura 2. Roadmap tecnológico de matérias-primas renováveis : (a) médio prazo; (b) médio prazo - continuação

interessadas no desenvolvimento do mercado e procuram alternativas de aplicações e de tecnologias de produção. Existem esforços em 


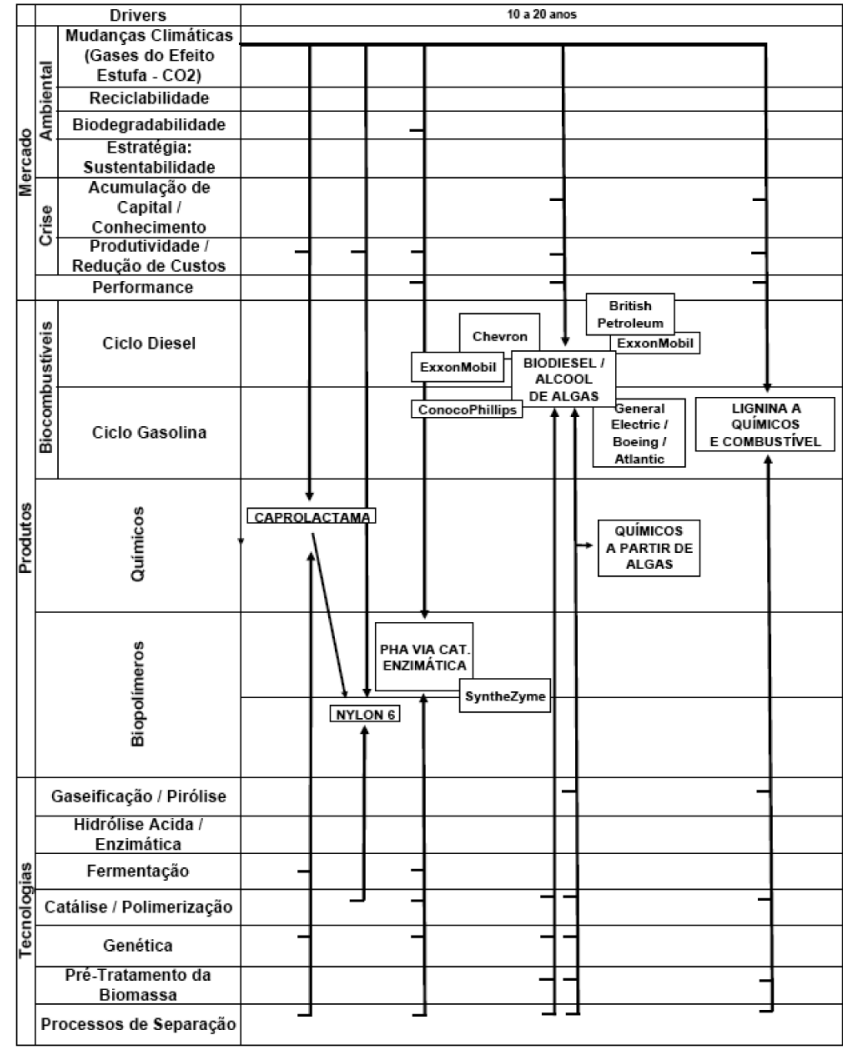

Figura 3. Roadmap tecnológico de matérias-primas renováveis - longo prazo

curso buscando melhores propriedades e processos de produção mais simples, de forma a tornar o PLA mais competitivo no mercado.

Dois outros biopolímeros - PHA e PHB - estão em início de comercialização. A Metabolix, empresa de biotecnologia americana, em associação com a ADM (Telles) anunciou planta de 50.000 ta para produção de PHA, para operação no final de 2009. PHA e PHB (Biocycle-empresa brasileira) são polímeros obtidos diretamente de micro-organismos e já produzidos comercialmente. Custos associados a dificuldades no controle do processo de produção e propriedades inadequadas respondem pela baixa penetração no mercado.

Cargill e Dow estão trabalhando no desenvolvimento e colocação no mercado de polióis verdes baseados em óleos vegetais e utilizados para a confecção de poliuretanos. Myriant está desenvolvendo a produção de ácido succínico.

\section{Período 2015-2019}

Assume-se, com base nos investimentos anunciados e no estágio atual da tecnologia, que o processo de obtenção de etanol a partir de celulose estará disponível no período entre 2015 e 2019. Com apoio do DOE, alguns projetos americanos são anunciados em escala comercial para o período: Abengoa, Iogen, Poet, pela via bioquímica, e Range Fuels, pela via termoquímica, entre outros. Alguns desses projetos têm previsão inicial de operação antes de 2015, mas dificuldades tecnológicas e de custo ainda existentes justificam que se considere o amadurecimento do etanol celulósico apenas em médio prazo. Petrobras está finalizando o projeto básico para uma planta piloto para produção de etanol a partir do bagaço de cana.

$\mathrm{Na}$ produção de etanol celulósico tem merecido destaque o processo combinado termo-bioquímico (gaseificação + fermentação do gás de síntese) da Coskata. Uma unidade de demonstração está operando e anuncia-se a construção de unidade comercial nos EUA. INEOS teria desenvolvido tecnologia similar e também anuncia plantas comerciais em médio prazo.
Outra tecnologia que deverá estar disponível nesse período é a de produção de hidrocarbonetos superiores (na faixa da gasolina e diesel) a partir de MPR. Na rota bioquímica pode ser citada a tecnologia da Amyris para produção de isoprenoides a partir de açúcares (fermentação) que possui planta piloto operando no Brasil. Outros projetos com objetivos semelhantes, utilizando outros conceitos têm surgido: LS9, Virent e KIOR. O grande ponto de atração desses projetos é a qualidade dos combustíveis produzidos que são substitutos "perfeitos" dos derivados do petróleo, o que os tornaria superiores ao etanol. Além de serem utilizados diretamente, sem necessidade de qualquer adaptação nos motores, não demandam também a construção de infraestrutura dedicada de transporte e distribuição.

O hidroximetilfurfural (HMF) é visto como um dos mais promissores compostos derivados de biomassa em razão do seu potencial como plataforma para novos produtos químicos e polímeros, além de combustíveis. Existe um fluxo importante de publicações científicas explorando a produção do HMF a partir da glicose e frutose e, mais recentemente, a partir da celulose. A simplicidade da transformação química da lignocelulose em HMF contrasta com a complexidade da rota bioquímica, o que parece estar atraindo uma atenção crescente para o HMF. Entretanto, ainda são poucas as iniciativas de projetos voltados para sua produção e comercialização. Notem-se as iniciativas da empresa holandesa Avantium, que parece ter uma base efetiva de expertise na tecnologia de furânicos. Avantium têm procurado estabelecer alianças para complementar sua expertise tecnológica. Registram-se alianças com Royal Cosun para apoio na seleção e isolamento de matérias-primas provenientes de resíduos agrícolas e com Natureworks (Cargill) para apoio no desenvolvimento de mercados e aplicações da linha de biopolímeros furânicos que a Avantium pretende produzir.

\section{Período 2019-2030}

Acredita-se que a produção em maior escala de biocombustíveis e bioprodutos a partir de algas somente venha a ocorrer comercialmente após 2019. Existem ainda desafios a serem vencidos nas áreas de genética e engenharia. Em médio prazo, devem surgir apenas alguns projetos pioneiros voltados para produtos especiais ou atraídos pelo abatimento de $\mathrm{CO}_{2}$.

A obtenção de caprolactama via processos fermentativos poderá levar à produção competitiva de um nylon 6 verde.

A disponibilidade de lignina em decorrência dos processos de utilização da celulose deve gerar um interesse crescente no seu aproveitamento. Alguns produtos potenciais foram identificados e destacados por Holladay et al.: ${ }^{21}$ aditivos para combustíveis, produção de corrente de benzênicos BTX (que poderia ser tratada em unidades hoje disponíveis em centrais e refinarias petroquímicas), obtenção de fenóis e resinas fenólicas e produção de fibra de carbono. Vislumbrase a produção de uma fibra de carbono de baixo custo que poderia encontrar grande mercado na indústria automobilística.

\section{DINÂMICA DA INOVAÇÃO EM BIOCOMBUSTÍVEIS, BIOPRODUTOS E BIORREFINO}

As informações levantadas e processadas na seção anterior propiciam uma discussão da dinâmica do processo de inovação que se desenrola na construção da indústria baseada em MPR. Apresenta-se a seguir uma síntese dessa discussão.

No presente estágio de desenvolvimento das tecnologias não é possível antecipar as inovações que vão ser efetivamente adotadas no mercado de combustíveis e de bioprodutos. Trata-se de um processo voltado para a geração de variedades que, dentro da dinâmica da inovação, serão selecionadas ao longo do tempo e contribuirão para a construção da indústria baseada em biomassa do futuro. Os 
projetos em desenvolvimento se voltam para a busca de melhores produtos, melhores processos e melhores matérias-primas (de preços mais baixos e estáveis, e de fácil disponibilidade) para a produção de biocombustíveis que possam superar as limitações atuais da indústria e de bioprodutos que possam se apresentar como alternativas aos produtos de base fóssil.

Alguns pontos devem ser destacados. O primeiro refere-se à quantidade e diversidade das alternativas propostas, o que sugere que a tecnologia se encontra na fase fluida. Não foram ainda definidos os processos e produtos que vão ocupar a maior parcela do mercado.

No que se refere à natureza das inovações, devem ser observados os aspectos relacionados às matérias-primas, aos processos e produtos.

Quanto às matérias-primas, os esforços se concentram na melhoria da produtividade de matérias-primas de diversos tipos utilizando conhecimentos de biotecnologia e engenharia genética. São desenvolvidas pesquisas em matérias-primas já consagradas, como a cana-de-açúcar, e em matérias-primas ainda não utilizadas largamente pela indústria, como os materiais celulósicos, as algas e novas plantas. Novos modelos de negócios utilizando o lixo como matéria-prima têm sido testados. ${ }^{22}$

A análise das inovações de processo mostra, em primeiro lugar, uma amplitude de técnicas em desenvolvimento, utilizando diversas bases de conhecimento (fermentação, processos enzimáticos, catálise, engenharia genética, gaseificação, síntese química). A variedade de processos aponta ainda para a presença de empresas com backgrounds variados de conhecimento e que tradicionalmente não estavam presentes nos mercados de energia e de química. É o caso das empresas de biotecnologia, algumas com histórico de desenvolvimentos importantes em outras indústrias, como a farmacêutica.

A indústria de combustíveis líquidos costuma ter sua atenção voltada para as inovações de processo. Nessa linha, boa parte dos esforços está voltada para se desenvolver novos processos para a produção de combustíveis já conhecidos e utilizados, como o etanol. Mas o estágio atual da indústria vislumbra oportunidades de introduzir novos produtos, de origem renovável, que se aproximem da condição de combustíveis ideais e de outros bioprodutos que possam competir com produtos químicos de base fóssil.

Deve ser ainda mencionada a crescente importância do conceito de biorrefinaria. Esse conceito sugere que a exploração das MPR precisa integrar uma visão multiproduto, explorando diversas correntes e processos, à semelhança das refinarias de petróleo. No caso da biorrefinaria, os produtos energéticos aparecem ao lado de produtos químicos.

É intereressante observar as empresas envolvidas e a variedade de abordagens estratégicas. Destacam-se as empresas que contribuem com o seu conhecimento tecnológico de base: empresas de biotecnologia em primeiro lugar, outras empresas de base tecnológica, empresas de química (Du Pont) e de enzimas (Novozyme, Genencor). Outro grupo importante é o das empresas detentoras de ativos complementares estratégicos (operação em escala, distribuição, comercialização, utilização): as empresas de petróleo, as montadoras e as empresas agroindustriais são os principais exemplos.

\section{CONCLUSÕES}

Este artigo apresentou um roadmap sobre matérias-primas renováveis (rMPR) desenvolvido pela Braskem e discutiu o seu conteúdo e implicações. O rMPR é visto como um exercício inicial cujo resultado é aberto às discussões e contribuições dentro da empresa e no ambiente externo dos grupos de interesse. O presente artigo cumpre parte desse propósito ao apresentar o processo de construção do rMPR, divulgar e discutir a sua versão inicial.
O objetivo central do rMPR é de ser um documento aberto para discussão do uso de matérias-primas renováveis nas indústrias de energia e química. Espera-se que, a partir de uma visão da indústria no mundo, o documento possa evoluir e representar uma base para a elaboração de políticas de ciência, tecnologia e inovação para a indústria baseada em MPR no Brasil.

Quanto ao conteúdo em si do rMPR, cabe destacar que o seu ponto central é a percepção de que a utilização de biomassas para a produção de biocombustiveis e de bioprodutos deve crescer e ter peso significativo na economia. Os biocombustíveis são o driver principal desse mercado e deverão definir os volumes demandados, mas o conceito em construção e que abre um grande número de oportunidades é o de aproveitamento integrado das biomassas para a geração de combustíveis, produtos químicos e eletricidade.

É notável a multiplicidade de rotas e soluções tecnológicas em desenvolvimento e que, de certa forma, estão em competição como candidatas a soluções vencedoras do processo de desenvolvimento e difusão das inovações. Destaque-se o impulso que a chamada white biotech começa a ter, mas alternativas como as rotas termoquímicas ou químicas estão presentes como opções tecnológicas possíveis; sem falar da combinação entre essas rotas. Uma grande atenção aos indicadores de evolução de mercados (apostas, comprometimentos, marcos regulatórios) e às indicações de amadurecimento e aprendizado das alternativas tecnológicas deve ser desenvolvida tanto pelas empresas quanto pelas agências governamentais responsáveis pelas políticas de fomento ao setor.

$\mathrm{Na}$ atual fase da indústria, algumas características das iniciativas das empresas e agências governamentais devem ser enfatizadas. Do ponto de vista das agências, destaque-se o peso que tiveram e continuam tendo, em particular as ligadas à energia nos EUA (DOE, NREL, entre outros), na definição de agendas claras de pesquisa, muitas vezes com metas de desempenho a serem atingidas e alocação de recursos para os empreendimentos. Do ponto de vista das empresas, dois pontos são marcantes. O primeiro é a presença constante de associações em que se busca valorizar a complementaridade das competências. A segunda é a presença de novos players - a maioria com origem na biotecnologia e no agribusiness - que tomam iniciativas nos mercados de energia e de química. Na atual etapa da indústria, esses novos players têm convivido com as tradicionais empresas de energia e química, em associação com elas ou não. Somente o amadurecimento da indústria indicará se novos competidores efetivamente surgirão ou se a base tecnológica trazida pelas novas empresas será absorvida pelos players estabelecidos em energia e química, apoiados em seus ativos complementares.

Finalmente, cabe destacar que a mudança de base de matériaprima na indústria química (ou pelo menos o aumento significativo da importância de uma nova base de matéria-prima) é uma oportunidade histórica rara que empresas e países podem ter para modificar em seu favor as posições de liderança na indústria. Nessa direção, os indispensáveis esforços tecnológicos se associam à capacidade de perceber e influenciar as mudanças na organização da indústria e na estrutura produtiva.

A posição brasileira parece, portanto, viver um momento de definição. A indústria sucro alcooleira brasileira apresenta hoje um alto grau de desenvolvimento tecnológico, o que leva o país a ter uma grande vantagem competitiva. $\mathrm{O}$ cenário apresentado acima leva a crer que as tecnologias de aproveitamento da biomassa deverão dar um salto nos próximos anos. A questão que se impõe é: conseguiremos acompanhar este processo? Serão as vantagens competitivas da indústria baseada em matérias-primas renováveis da mesma natureza das que detêm hoje a indústria brasileira? O roadmap apresentado sugere uma sofisticação e uma maior complexidade dessa base tecnológica. 
No que se refere especificamente às políticas de ciência, tecnologia e inovação voltadas para as matérias-primas renováveis no Brasil, é importante sublinhar que o cenário descrito pelo rMPR apresenta uma indústria baseada em MPR em grande dinamismo e evolução. Essa indústria tende a ser no futuro notavelmente diferente da que conhecemos hoje, baseando-se em tecnologias proprietárias e mais sofisticadas e complexas se comparadas às de primera geração atualmente utilizadas. Assim, as políticas brasileiras precisam ter como balizamento a construção de uma posição de liderança na indústria do futuro e não se limitar à defesa de posições atuais. Nossas vantagens comparativas - matéria-prima, produção competitiva em escala, mercado de biocombustíveis, entre outras - são admiráveis mas não se transferem automaticamente em vantagerns competitivas na indústria do futuro que se apoia em novos fatores de competitividade.

\section{MATERIAL SUPLEMENTAR}

Além da seção "Nota metodológica: Roadmaps tecnológicos e a construção do rMPR", são apresentadas extensões das seguintes seções que foram desenvolvidas de forma sucinta no texto do artigo: "Drivers para a utilização crescente de MPR", "Evolução dos mercados" e "Dinâmica da Inovação em Biocombustíveis, Bioprodutos e Biorrefino". Está disponível em http://quimicanova.sbq.org.br, na forma de arquivo PDF, com acesso livre.

\section{REFERÊNCIAS}

1. Willyard, C.; McLees, C.; Res. Manage. 1987, Sep/Oct, 13.

2. Phaal, R.; Farrukh, C.; Probert D.; Technol. Forecast. Soc. Change 2004, 67,5 .

3. Yasunaga, Y.; Watanabe, M.; Korenaga, M.; Technol. Forecast. Soc. Change 2009, 76, 61.

4. Phaal, R.; (2009) Public-domain roadmaps, http://www.ifm.eng.cam. ac.uk/ctm/trm/documents/published_roadmaps7_6_09.pdf, acessada em Fevereiro 2011.
5. Albright, R.; Kappel, T.; Res. Technol. Manag. 2003, 46, 31.

6. Grossman, D.; Res. Technol. Manag. 2004, 47, 41.

7. Phaal, R.; Muller, G.; Technol. Forecast. Soc. Change 2009, 76, 39.

8. Christensen, C.; Innovator's dilemma, $1^{\text {st }}$ ed., HBS Press: Boston, 1997.

9. Kostoff, R.; Boylanb, R.; Simons, G.; Technol. Forecast. Soc. Change 2004, 71, 141.

10. Phaal, R.; Farrukh, C.; Probert, D.; Res. Technol. Manag. 2004, 47, 26.

11. Liska, A. J.; Yang, H. S.; Bremer, V. R.; Klopfenstein, T. J.; Walters, D. T.; Erickson, K. G.; Cassman, K. G.; J. Ind. Ecol. 2009, 13, 58; UNEP United Nations Environmental Program, Towards sustainable production and use of resources: assessing biofuels, 2009, http://www.unep.fr/scp/ rpanel/pdf/Assessing_Biofuels_Full_Report.pdf. acessada em Fevereiro 2011

12. West, J.; E. I. Du Pont de Nemours and Company (A), case n.9-699-037, Harvard Business School Press: Boston, 1999; Holliday, C.; Harvard Bus. Rev. 2001, 79, 129.

13. DOE Biomass program; www1.eere.energy.gov/biomass, acessada em Fevereiro 2010.

14. Riese J.; White biotechnology, http://www.dsm.com/en_US/downloads/ sustainability/white_biotech_mckinsey_feb_2009.pdf, acessada em Fevereiro 2011.

15. Roadmap for bioenergy and biobased products in the United States BRDI, http://www1.eere.energy.gov/biomass/pdfs/obp_roadmapv2_web. pdf, acessada em Fevereiro 2011.

16. Shen, L.; Worrel, E.; Patel, M.; Biofuels, Bioprod. Bioref. 2010, 4, 25.

17. Wilson, D. B.; Curr. Opin. Biotechnol.2009, 20, 295.

18. Darzins, A.; Garofalo, R.; Biofuels, Bioprod. Bioref. 2009, 3, 426.

19. IEA Bioenergy; From $1^{\text {st }}$ to $2^{\text {nd }}$ generation biofuel technologies, OECD: Paris, 2008.

20. Bohlman, G. M.; Chem. Eng. Prog. 2005, 101, 37.

21. Holladay J. E.; White J. F.; Bozel J. J.; Johnson D.; Pacific Northwest National Laboratory, 2007, http://www.pnl.gov/main/publications/ external/technical_reports/PNNL-16983.pdf, acessada em Fevereiro 2011.

22. McBride E.; A special report on waste, The Economist 2009, $26^{\text {th }}$ Feb. 
ROADMAP TECNOLÓGICO EM MATÉRIAS-PRIMAS RENOVÁVEIS: UMA BASE PARA A CONSTRUÇÃO DE POLÍTICAS E ESTRATÉGIAS NO BRASIL

\author{
Paulo Coutinho \\ IDEOM/BRASKEM, Av. das Nações Unidas, 8501, 24 andar, 05425-070 São Paulo - SP, Brasil \\ José Vitor Bomtempo*
}

Escola de Química, Universidade Federal do Rio de Janeiro, Av. Horácio Macedo, 2030, Bl. E, Ilha do Fundão, 21941-909

Rio de Janeiro - RJ, Brasil

\section{Nota metodológica: Roadmaps tecnológicos e a construção do roadmap matérias-primas renováveis (rMPR)}

\section{Conceituação e formatos dos roadmaps}

Os roadmaps tecnológicos começaram a ser usados no final dos anos 1970, na Motorola. ${ }^{1}$ Nas últimas 3 décadas, o conceito se difundiu largamente, ultrapassando a utilização pelas empresas e adquirindo muitas vezes um caráter interorganizacional. Hoje os roadmaps são largamente utilizados por países (EUA, Coreia, Japão, Reino Unido, etc) e empresas (GE, Siemens, GM, Shell, etc). No Brasil, a ferramenta vem sendo adotada na identificação e planejamento de áreas prioritárias do governo (CGEE e ABDI, por exemplo) e mesmo pela Petrobras.

Os roadmaps costumam ser vistos segundo duas perspectivas principais: a perspectiva da empresa e a perspectiva interorganizacional. ${ }^{2} \mathrm{Na}$ primeira, busca-se integrar desenvolvimento tecnológico e planejamento do negócio, avaliar o impacto de novas tecnologias e as correspondentes evoluções dos mercados. Na perspectiva interorganizacional, busca-se compreender um determinado ambiente tecnológico e avaliar as ameaças e oportunidades para os grupos de interesse na referida área tecnológica. Os roadmaps tornam-se assim instrumentos das políticas governamentais de inovação que visam promover a convergência tecnológica e construir a colaboração entre diferentes setores. Esse processo traz novos desafios na construção e utilização dos roadmaps, que não são particularmente presentes nos usos empresariais. ${ }^{3}$ Muitos dos roadmaps interorganizacionais costumam ser divulgados como forma de criação de uma plataforma de discussão de um tema tecnológico relevante entre os grupos de interesse. Phaal ${ }^{4}$ identificou mais de 1.500 roadmaps, em sua maioria interorganizacionais, disponíveis para consulta livre na internet.

Qualquer que seja a perspectiva - de empresa ou interorganizacional - um roadmap é a representação de uma visualização do futuro que procura integrar os aspectos relevantes do negócio (mercados, produtos, tecnologias, processos e pessoas) na dimensão tempo. O roadmap é, portanto, uma representação gráfica baseada no tempo, compreendendo um número de camadas que tipicamente incluem perspectivas comerciais e tecnológicas. Diversas formas de representação podem ser utilizadas. ${ }^{2,3,-7}$ Encontram-se roadmaps em múltiplos níveis, barras, tabelas, gráficos, figuras, fluxogramas, único nível e texto.

\footnotetext{
*e-mail: vitor@eq.ufrj.br
}

Uma característica valiosa dos roadmaps está na sua apresentação concisa. A sua natureza visual tem especialmente ajudado na discussão estruturada e construtiva de processos de prospecção tecnológica tanto no âmbito das políticas, envolvendo múltiplas organizações e atores, quanto no âmbito das estratégias empresariais, envolvendo as atividades da organização, normalmente em seu ambiente de planejamento tecnológico.

\section{Roadmaps e a utilização de matérias-primas renováveis}

A contribuição dos roadmaps às organizações, sejam elas empresas ou organismos governamentais, se dá principalmente pela orientação que propiciam ao monitoramento do ambiente e à avaliação e acompanhamento de tecnologias específicas. Incluem-se aqui as tecnologias de ruptura, ${ }^{8}$ que podem ter o potencial de redefinir uma indústria ou eventualmente de criar uma indústria inteiramente nova. Os roadmaps de tecnologias de ruptura ${ }^{9}$ podem ser particularmente úteis no cenário atual das indústrias química e de energia. Diversas alternativas de processos e produtos encontram-se em desenvolvimento e em competição para se tornarem opções comerciais para a utilização de MPR. O caráter de ruptura desse processo precisa ser monitorado e trazido para um debate entre os grupos de interesse, de modo a criar condições para a construção de políticas e estratégias. No caso brasileiro, a criação dessas condições pode ser defendida como de grande importância para a posição que a indústria brasileira pode vir a ocupar na indústria do futuro. É essa a proposição do roadmap cuja metodologia de elaboração é apresentada a seguir.

\section{Método de construção do rMPR}

O processo de construção dos roadmaps é muitas vezes tão importante quanto o documento final. ${ }^{2}$ Por isso, a interação e a dinâmica de participação dos grupos envolvidos, durante e após a elaboração do roadmap, devem ser cuidadosamente consideradas na metodologia. Existem muitas proposições de metodologia na literatura. Este artigo toma como referência duas das mais conhecidas e utilizadas: a de Albright e Kappel ${ }^{5}$ e a de Phaal, Farrukh e Probert. ${ }^{10}$ Essas metodologias, desenvolvidas por meio de diversos projetos de construção de roadmaps empresariais, foram adaptadas ao caso do rMPR.

Dois pontos em particular foram centrais na construção do rMPR. O primeiro está relacionado à dificuldade de obter visões de médio e longo prazo dos profissionais envolvidos com o dia a dia das empresas. A visão desses profissionais, intensamente solicitados pelas questões imediatas, tende a uma perspectiva de curto prazo. $\mathrm{O}$ segundo ponto 
decorre do risco de transformar o roadmap num exercício estático. O mercado e a tecnologia, principalmente em casos como o das MPR, devem ser tratados como "vivos" e em constante mutação. Existe nos exercícios prospectivos o risco de se limitar à geração de um documento final que traduz apenas a visão de momento. Torna-se assim imperativo divulgar o documento e promover foros de discussão para que o próprio roadmap possa, ao mesmo tempo, acompanhar a dinâmica da indústria e envolver os diversos grupos de interesse. Com isso, o rMPR ultrapassa os limites da empresa e pode atingir o seu objetivo de ser uma plataforma de discussão do problema.

\section{Drivers para utilização crescente de MPR}

Diversos fatores podem ser vistos como determinantes do interesse crescente pelas MPR, entre os quais os de maior peso são: o potencial da biologia industrial ou white biotechnology, as restrições ambientais ao uso de matérias-primas fósseis, a orientação das estratégias empresariais e a perspectiva da inovação tecnológica como saída de crise.

A biologia está se tornando um poderoso vetor de dinamismo da economia mundial, como base da inovação no século XXI. A evolução dos conhecimentos em biologia contribui para maior utilização da biomassa, seja na preparação e produção de matérias-primas, nas tecnologias de conversão e mesmo na obtenção de novos produtos. Novos conhecimentos baseados em engenharia genética, novos processos fermentativos e enzimáticos estarão crescentemente disponíveis.

A questão ambiental é, sem dúvida, outro fator de peso no aumento do interesse pelas MPR. Apesar das dificuldades políticas que têm cercado as decisões dos grandes foros internacionais, pode ser tomada como consensual a ideia de que as restrições ambientais ao uso de tecnologias que contribuam para o aquecimento global serão crescentes nos próximos anos. Em consequência, espera-se que as metas de utilização de biocombustiveis sejam mantidas e implementadas. Entretanto, em resposta aos debates e críticas que têm atingido os chamados biocombustíveis de primeira geração, vislumbra-se que os biocombustíveis do futuro podem vir a ser novos produtos, produzidos a partir de novas matérias-primas e novos processos de conversão. Uma consequência da confirmação do mercado dos biocombustíveis, principalmente do etanol, é a viabilização de biorrefinarias integradas, em substituição à produção única de combustíveis, como conceito de exploração de biomassa. Tem se consolidado a ideia de que as biorrefinarias, produzindo biocombustíveis e outros produtos (produtos químicos e bioeletricidade), contribuiriam para viabilizar economicamente a exploração da biomassa e melhorar os resultados ambientais (balanço energético e redução de emissão de gases do efeito estufa) dos processos. ${ }^{11}$

As orientações estratégicas definidas por algumas empresas importantes reforçam o processo de construção de uma indústria baseada em biomassa. Du Pont estabeleceu, já em 1998, princípios de sustentabilidade para a sua trajetória de crescimento no século XXI que se baseiam fortemente na biotecnologia e na utilização de MPR. ${ }^{12}$ Mais recentemente, a BASF também passou a identificar em seus documentos estratégicos a biotecnologia e as MPR como uma das bases do crescimento futuro da empresa. Devem ser destacadas ainda iniciativas da Dow, DSM e Novozymes. No âmbito brasileiro, Petrobras, Braskem, Oxiteno e Quattor têm projetos e iniciativas em MPR. Não se pode deixar de mencionar ainda as empresas de petróleo que têm investido na base tecnológica em biocombustíveis, o que guarda relação direta com a construção da indústria de aproveitamento de biomassa do futuro.

No campo das estratégias deve ser destacada a importância de segmentos utilizadores chave como embalagens e automóveis. $\mathrm{O}$ anúncio recente da Coca-Cola da chamada plantbottle, que deverá conter até $30 \%$ de material baseado em fontes renováveis, é uma indicação expressiva das tendências estratégicas relacionadas às MPR. Movimentos de empresas como a Coca-Cola podem contribuir de forma decisiva para o estabelecimento de novos conceitos que podem se difundir pela economia. No segmento de embalagens sustentáveis têm sido registradas muitas iniciativas das empresas mais diretamente ligadas ao consumidor final, como os produtores de alimentos e os grandes distribuidores. Isso sugere a existência de oportunidades de atuação para as empresas químicas capazes de oferecer novos materiais e novos conceitos de embalagens.

No caso da indústria automobilística, duas tendências fortes influenciam as perspectivas da utilização de produtos derivados de MPR. A primeira refere-se à redução de emissões e melhora de eficiência ambiental dos carros. Nesse ponto, os biocombustíveis encontram-se em competição com os carros elétricos que merecem, atualmente, grande destaque nas estratégias da indústria automobilística. No que se refere aos materiais estruturais, algumas montadoras anunciam em seus relatórios de sustentabilidade metas de utilização de biomateriais, como é o caso da Toyota que tem como meta utilizar materiais renováveis ou reciclados em $15 \%$ das peças em resinas.

A segunda tendência forte está relacionada à perspectiva de crescimento da indústria que se volta para os mercados emergentes. Nesses mercados, a necessidade de reduzir custos e produzir carros adaptados às condições locais abre oportunidades de inovações que podem oferecer oportunidades aos biocombustíveis e bioprodutos.

Por fim, cabe ressaltar que a inovação tecnológica é vista historicamente como estratégia de saída de crise. Os períodos de crise já foram aproveitados no passado por países e empresas para redesenhar suas posições no mercado. $\mathrm{O}$ extraordinário projeto $\mathrm{Du}$ Pont que resultou no nylon foi um projeto de pesquisa fundamental desenvolvido nos anos 30 em plena depressão econômica. Atualmente, as manifestações do governo americano em relação à busca de liderança em novas fontes de energia e, mais concretamente, os recursos alocados pelos programas voltados para os biocombustíveis avançados ${ }^{13}$ reforçam a ideia de que as inovações em MPR podem ter peso na recuperação da economia.

Mesmo se fatores como preços baixos de petróleo, não avanço das restrições ambientais ou perda de espaço dos biocombustíveis em função de outras soluções para o transporte - como os carros elétricos, por exemplo - podem representar uma possibilidade de redução dos esforços em utilização das MPR, as previsões e estudos existentes sugerem que os fatores favoráveis acima apontados continuarão a pesar nas próximas décadas. As previsões de evolução dos principais mercados, apresentadas a seguir, confirmam essa tendência.

\section{Evolução dos mercados}

A evolução do mercado de produtos derivados das MPR deve considerar em perspectiva três vetores interrelacionados, mas que podem ter dinâmicas próprias: os biocombustíveis para transporte, os bioprodutos em geral, e os biopolímeros em particular.

\section{Crescimento esperado dos biocombustíveis}

Os biocombustíveis hoje comercializados são o bioetanol e o biodiesel. Contrariamente à indústria do etanol, já consolidada e mundialmente considerada a referência do setor, a indústria brasileira de biodiesel é recente e ainda se encontra em estruturação. Mediante rotas biológicas, o bioetanol pode ser produzido com base em qualquer biomassa que contenha quantidades significativas de amido (milho, trigo e outros cereais e grãos) ou açúcares (cana e beterraba).

Projeta-se um crescimento da ordem $14 \%$ a.a. para os biocombustíveis líquidos nos próximos 5 anos, sendo o mercado atual da ordem de US\$ 26 bi. ${ }^{14}$ Para o mercado americano em particular, 
existe uma previsão de incorporação de biocombustíveis avançados que corresponde a uma taxa anual média de crescimento da ordem de $10 \%$ para os próximos 20 anos. ${ }^{15}$

\section{Crescimento esperado de bioprodutos}

A definição de bioprodutos pode ser bastante diversa. Podem ser identificados 3 grupos: tradicionais, produzidos por fermentação e produzidos por processos enzimáticos.

O primeiro grupo inclui borracha natural, óleos essenciais e extratos naturais, produtos botânicos, nutracêuticos, hidrocoloides, PUFAs (ácidos graxos poli-insaturados) e oleoquímicos. É certamente o mais volumoso hoje, com um mercado estimado em cerca de US\$ 35 bi. ${ }^{14} \mathrm{O}$ crescimento esperado é relativamente modesto e não inclui, na maioria dos casos, produtos ou processos inovadores.

De maior interesse para a identificação dos mercados da chamada white biotech são os produtos químicos por fermentação e por processos enzimáticos. Esses dois grupos representam hoje um mercado estimado em US\$ 15 bi. Incluem-se aqui a introdução e o crescimento de novos biopolímeros, de produtos químicos convencionais, inclusive produtos de volume, a partir de rotas biológicas. Estima-se um potencial de crescimento anual de $8 \% .{ }^{14}$

É interessante cotejar essa visão do mercado mundial com a visão do mercado americano projetada para um período mais longo. Bioprodutos são definidos aqui como qualquer produto gerado a partir de biomassa, que poderiam de outra forma ser produzidos usando matérias-primas fósseis. O mercado americano de bioprodutos hoje se situa em cerca de 10 milhões de toneladas. Espera-se que atinja 25 milhões em 2030, o que corresponde a uma taxa de crescimento anual, em volume, de $4,3 \% .^{15}$

\section{Crescimento esperado de biopolímeros}

Os biopolímeros incluem os polímeros extraídos diretamente da biomassa, com ou sem modificação (ex.: derivados da celulose e do amido), produzidos diretamente de micro-organismos no seu estado natural ou modificados geneticamente (ex.: PHA, PHB), novos polímeros obtidos a partir de biointermediários (PLA, Green $P E T$ ), plásticos biodegradáveis obtidos por aditivação de plásticos convencionais (Ecoflex, poliéster biodegradável da BASF) e plásticos convencionais produzidos a partir de MPR (biopolietileno).

O crescimento relativo desses biopolímeros dependerá ainda da definição de sustentabilidade que vier a ser estabelecida nas normas ambientais. Se a definição se der com base na carga de gases de efeito estufa gerados, o espaço de biopolímeros convencionais a partir de fontes renováveis sustentáveis (ex: polietileno a partir de etanol de cana) pode crescer de forma significativa. Se, entretanto, prevalecer uma visão de contestação da utilização de plásticos em razão da poluição visual gerada, o segmento pode favorecer os ditos biodegradáveis, como o PLA. Esse debate ainda não está formulado com clareza na sociedade. Deve ser assinalado que grandes consumidores de plásticos, como indústrias de alimentos e supermercados, para responder às pressões ambientais sobre seus produtos, têm optado por embalagens sustentáveis baseadas em polímeros biodegradáveis.

As estimativas do mercado atual de biopolímeros são, em razão das diferentes definições adotadas, bastante discrepantes. De modo geral, o mercado europeu encontra-se bem mais desenvolvido do que o americano. Destaque-se em particular o potencial de crescimento dos biopolímeros. No período 2003 a 2007 a capacidade de produção cresceu na faixa de $40 \%$ ao ano e o potencial técnico de substituição de plásticos petroquímicos por bioplásticos é estimado em $90 \%{ }^{16}$ Destaquem-se as elevadas taxas de crescimento dos bioplásticos biodegradáveis, como PLA e outros, que são atualmente da ordem de $17 \%$ ao ano. ${ }^{16}$

O potencial de crescimento dos bioplásticos é ainda refletido na evolução do mercado de embalagens, no qual as embalagens ditas sustentáveis têm crescimento esperado para os próximos anos na faixa de $25 \%$ ao ano. Entretanto, o conceito de embalagem sustentável não está ainda claramente estabelecido. Como discutido acima, pode-se identificar aqui uma oportunidade aberta que dependerá de um complexo processo de formação de opinião e de regulamentação. As empresas químicas inovadoras podem encontrar uma oportunidade de atuação proativa na cadeia das embalagens plásticas, participando do processo de desenvolvimento de novos conceitos de embalagem sustentável que venham a utilizar seus materiais.

\section{Dinâmica da inovação em biocombustíveis, bioprodutos e biorrefino}

A evolução dos mercados, das tecnologias e dos produtos, como visto no rMPR, sugere a existência de um movimento de amplitude expressiva, em termos dos esforços de pesquisa e de inovação, voltado para a indústria de biocombustíveis e de aproveitamento integral da biomassa. Esse movimento pode ser de importância crucial na moldagem da indústria de biocombustíveis e bioprodutos do futuro. Assim, sua compreensão é chave para a elaboração de políticas voltadas para a área.

A análise desenvolvida nesta seção está organizada em torno das seguintes dimensões:

- a quantidade e diversidade das alternativas propostas,

- a natureza das inovações, destacando as particularidades relacionadas a matérias-primas, processos e produtos,

- o perfil e as estratégias das empresas (background do conhecimento, associações, empresas de base tecnológica, novos entrantes e grandes empresas estabelecidas).

\section{A variedade de alternativas}

Numerosas iniciativas têm sido lançadas para responder aos desafios e explorar as oportunidades que as matérias-primas renováveis oferecem. O desafio é a produção de combustíveis líquidos, bioprodutos e bioenergia, atuando, de forma combinada ou não, no aumento de produtividade e modificação da própria biomassa e nas diversas alternativas de conversão da biomassa, rotas diretas ou em duas etapas, por via fermentativa, enzimática, química ou termoquímica, para se obter diferentes tipos de produtos.

A diversidade de propostas de inovações pode ser constatada, em primeiro lugar, nos diferentes tipos de matérias-primas: culturas existentes, novas culturas com finalidade energética e aproveitamento de resíduos de diversas origens e qualidades. Em cada um dos casos, por sua vez, diferentes abordagens e caminhos são propostos e experimentados, de forma combinada ou não: aumento de produtividade, utilização de terras e recursos não relacionados a alimentos, facilidade logística e preço. Cada uma dessas abordagens, por sua vez, pode trazer também uma variedade de formas para atingir os objetivos traçados, como mostram as múltiplas abordagens para cultivo e utilização das algas.

No nível das tecnologias de conversão, a variedade contempla rotas bioquímicas, termoquímicas ou químicas que podem, ainda, serem combinadas entre si em alguns processos. Mas a variedade ocorre ainda dentro de cada uma das rotas, como a utilização de enzimas e fermentações diversas ou as diferentes opções testadas para a gaseificação da biomassa e conversão em bio-óleo.

Como esperado, a variedade em produtos é menor. Entretanto, duas razões fazem com que o interesse pelas inovações de produto seja crescente. Em primeiro lugar, buscam-se cada vez mais combustíveis drop in, com desempenho próximo ou igual ao dos derivados convencionias, que não exigem modificações dos motores e aproveitam a infraestrutura de distribuição existente. Em segundo lugar, a 
diversificação da linha de produtos, associando combustíveis, de alto volume e baixos preços, com produtos químicos, de menor volume e de margens mais altas, tem aumentado o interesse por biorrefinarias integradas com múltiplos e novos produtos. Esses projetos estão em relativo atraso se comparados à produção dedicada de biocombustíveis. Mas o conceito é visto como central no futuro da indústria. Deve-se lembrar ainda que a diversificação de produtos favorece o desempenho ambiental dos processos, o que é crítico no caso de algumas matérias-primas como, por exemplo, o milho.

A combinação das múltiplas alternativas em matérias-primas, tecnologias de conversão e variedade de produtos compõe o quadro de diversidade que retrata o estágio atual da indústria baseada em MPR. Naturalmente, a forma como essa diversidade irá se traduzir em inovações difundidas no mercado de combustíveis e de bioprodutos não pode ser antecipada no presente estágio de desenvolvimento das tecnologias. Trata-se efetivamente de um processo voltado para a geração de variedades que, dentro da dinâmica da inovação, serão selecionadas ao longo do tempo e contribuirão para a construção da indústria baseada em biomassa do futuro.

\section{A natureza das inovações}

As inovações na utilização de MPR podem ser observadas em três níveis: matérias-primas, processos de conversão e produtos.

\section{Natureza das inovações: as matérias-primas}

A busca da matéria-prima ideal, ou de algumas matérias-primas ideais, está em aberto e evoluindo rapidamente. Os requisitos das matérias-primas incluem fatores múltiplos e não facilmente conciliáveis: disponibilidade, preço, qualidade em relação ao processo de conversão, sem esquecer a sustentabilidade ambiental.

No estágio atual parece claro que a cana-de-açúcar, cultivada nos níveis da produtividade brasileira, seria, entre as matérias-primas disponíveis, a mais próxima do ideal. Essa matéria-prima tem sido utilizada até agora apenas como fonte de etanol a partir da fermentação do caldo, além da produção de eletricidade a partir do bagaço. Entretanto, outras alternativas de combustíveis e bioprodutos a partir da cana como o diesel drop in da Amyris, o projeto Veranium/ BP de etanol celulósico ou o polietileno da Braskem têm surgido, reforçando o valor e potencial da cana-de-açúcar na indústria baseada em biomassa.

Outras culturas energéticas têm sido desenvolvidas como, por exemplo, switchgrass e miscanthus nos EUA e Canadá, e pinhão manso na Índia e outras regiões. O desenvolvimento dessas culturas tem sido difícil, como é da natureza das inovações, com esperanças e decepções que se alternam em resposta aos esforços dos pesquisadores e investidores. Parece claro que o processo de introdução do cultivo e uso de novas plantas exige um tempo de maturação que não pode ser ignorado e cujos resultados são incertos por natureza.

$\mathrm{Na}$ busca desses resultados uma via que tem sido privilegiada é o uso da engenharia genética e dos recursos da biotecnologia moderna para aumentar a produtividade e otimizar o balanço entre as características positivas e negativas das plantas. São desenvolvidas pesquisas em matérias-primas já consagradas, como a cana-de-açúcar, e em matérias-primas ainda não utilizadas largamente pela indústria, como os materiais celulósicos em geral, as algas e novas plantas. No caso de plantas ainda não utilizadas, o desenvolvimento é feito na expectativa de que os novos processos de conversão dos materiais celulósicos venham a se tornar comerciais. No caso do etanol, as inovações na produtividade da cana-de-açúcar reforçam os processos convencionais de produção além de reforçar a própria posição da cana-de-açúcar como matéria-prima de eleição.

Na busca de solução para o problema das matérias-primas, duas alternativas merecem no momento o foco das atenções: as algas, em primeiro lugar, e os resíduos urbanos, em particular os resíduos sólidos (municipal solid waste).

Apesar do grande interesse que a utilização de algas como matéria-prima para a produção de biocombustíveis e bioprodutos tem despertado recentemente, os problemas existentes, como mencionado na descrição do rMPR, exigem ainda importantes esforços de pesquisa e desenvolvimento para se atingir a almejada exploração em escala comercial. $\mathrm{O}$ atual estágio ainda seria predominantemente de apoio coordenado de agências governamentais, academia, empresas e investidores com vistas à passagem a escalas piloto e demonstração. Uma grande variedade de pesquisas, projetos e temas têm sido anunciados, mas ainda persiste uma disparidade de conceitos e custos que atestam a etapa fluida da tecnologia. De qualquer forma, os projetos em algas parecem sublinhar algumas tendências chave: produção de combustíveis drop in, diversificação para produtos de margens elevadas para aplicações especiais em química, farmácia e cosméticos, além de sustentabilidade ambiental inquestionável.

É também crescente o interesse na utilização do lixo como matéria-prima que se insere na construção de uma economia baseada na gestão dos resíduos. ${ }^{22} \mathrm{~A}$ perspectiva de novos modelos de negócios associando a solução desse difícil problema das cidades e a geração eficiente e sustentável de energia é uma das linhas em desenvolvimento.

No que se refere à produção de biocombustíveis, alguns projetos têm merecido a atenção dos analistas. O lixo tem grandes vantagens como matéria-prima no que se refere ao custo, que pode ser negativo, ao contrato de fornecimento, que pode ser estabelecido com as municipalidades em prazos compatíveis com a vida útil dos projetos, e à localização, que, sendo próxima ao mercado consumidor dos produtos gerados, simplifica o transporte e a necessidade de infraestrutura adicional. Os desafios da sua utilização, que se colocam então do lado das tecnologias de conversão, têm sido enfrentados por algumas empresas com projetos inovadores em diferentes estágios de maturação como os da Enerkem e Coskata, entre outros.

\section{Natureza das inovações: as tecnologias de conversão}

A análise das inovações de processo mostra, em primeiro lugar, uma amplitude de técnicas em desenvolvimento, utilizando diversas bases de conhecimento (fermentação, processos enzimáticos, engenharia genética, gaseificação, pirólise e, ainda, catálise e reações químicas), que traduzem o desafio dos biocombustíveis avançados de forma muito mais ampla do que a simples produção de etanol de celulose. Longe de ser irrelevante, a produção de etanol a partir de materiais lignocelulósicos é um desafio tecnológico importante e que vem sendo perseguido por diversas empresas, mas que não pode ser visto como sinônimo de biocombustíveis avançados, como parece ser às vezes a percepção dominante.

Cabe destacar que, ampliando o grau de variedade e multiplicidade das alternativas em jogo, mesmo tecnologias de conversão de mesma natureza apresentam variantes em desenvolvimento. A via bioquímica pode utilizar duas etapas (hidrólise e fermentação) para converter a lignocelulose em etanol ou procurar fazê-lo numa única etapa. A via termoquímica propõe diversas alternativas para a gaseificação, algumas inovadoras, como a gaseificação por plasma e por metal líquido, outras mais próximas das utilizadas comercialmente e, ainda, diversas opções para transformar o gás de síntese gerado em produto final, incluindo a mais conhecida conversão FT (Fisher-Tropsch) ou a ação de micro-organismos, como propõe Coskata. Ainda no campo dos tratamentos térmicos, não se pode deixar de mencionar a pirólise para produção de bio-óleo, que tem ganhado destaque ultimamente. Da mesma forma, os processos químicos continuam sendo testados e alguns projetos destacados têm proposto a utilização da hidrólise ácida para a produção de etanol a partir de lignocelulose (Bluefire) ou 
a conversão química de açúcares em combustíveis drop in (Virent). A rota química tem ainda sido mencionada em algumas pesquisas como alternativa para a produção de intermediários de síntese para a construção de plataformas químicas, como a do hidroximetilfurfural (HMF), que vem despertando interesse crescente.

A utilização de diferentes bases de conhecimento faz com que na maioria dos casos as empresas se vejam inevitavelmente em projetos que privilegiam uma das rotas, o que coloca um nível de incerteza elevado no futuro dessas empresas caso suas apostas venham a perder espaço na evolução da indústria. Algumas empresas e investidores de maior porte e disponibilidade de recursos têm tratado essa incerteza multiplicando suas apostas em diversas plataformas, com a perspectiva de desmobilizar eventualmente as que se mostrarem menos competitivas. É o caso, por exemplo, de Shell e Khosla Ventures. Outras empresas de porte e com volumes de investimento importantes em biocombustíveis e bioprodutos, entretanto, têm diversificando suas apostas de forma mais orientada em termos de tecnologia de conversão, focalizando determinadas áreas do conhecimento. É o caso, por exemplo, de BP e DuPont que se concentram na biotecnologia e nas rotas bioquímicas em suas diversas iniciativas.

A variedade de processos aponta ainda para a presença de empresas com backgrounds variados de conhecimento e que tradicionalmente não estavam presentes nos mercados de energia e de química. É o caso de forma notável das empresas de biotecnologia, algumas com histórico de desenvolvimentos importantes em outras indústrias, como a farmacêutica.

\section{Natureza das inovações: produtos}

Uma dimensão importante que pode ser evidenciada pela análise das propostas de inovação em desenvolvimento é a relacionada aos novos produtos. Inovações de produto são raras em combustíveis líquidos. A lógica natural da indústria é estabelecer especificações bem definidas de alguns produtos e buscar por meio de inovações de processos a redução de custo e a melhoria de características. Nessa linha, boa parte dos esforços é direcionada para novos processos e para a produção de combustíveis já conhecidos e utilizados, como o etanol. Mas o estágio atual da indústria vislumbra oportunidades de introduzir novos produtos, de origem renovável, que se aproximem da condição de combustíveis ideais e de outros bioprodutos que possam competir com produtos químicos de base fóssil. Um número crescente de projetos tem se interessado pela inovação de produto.

O problema da adaptação dos motores e da construção de infraestrutura de transporte e distribuição para o etanol e outros combustíveis de primeira geração tem aberto um espaço crescente para as inovações de produto com a produção de biocombustíveis drop in, o que valoriza os ativos complementares existentes. As discussões atuais sobre as limitações da infraestrutura americana para o etanol e as dificuldades para sua implementação reforçam essa tendência.

Ainda relacionado às inovações de produto, não pode deixar de ser mencionada a crescente importância do conceito de biorrefinaria. Esse conceito sugere que a exploração das MPR precisa integrar uma visão multiproduto, explorando diversas correntes e processos, à semelhança das refinarias de petróleo que derivam do óleo um conjunto variado de produtos. No caso da biorrefinaria, os produtos energéticos aparecem ao lado de produtos químicos. As biorrefinarias têm sido financiadas com empenho pelo governo americano (DOE e NREL). Também na Europa o número de iniciativas é expressivo. No Brasil, algumas iniciativas foram registradas de aproveitamento da cana-de-açúcar para a geração de outros produtos além do etanol. Citam-se os projetos da Oxiteno, da Dow e da Braskem. Essa tendência de valorização de bioprodutos ao lado de combustíveis de grande volume é vista como importante na indústria baseada em biomassa que seria, no futuro, centrada em processos integrados de biorrefino gerando biocombustíveis e outros bioprodutos.

\section{Empresas e estratégias}

Podem ainda ser observadas as empresas envolvidas nos desenvolvimentos e a variedade de perfis e abordagens estratégicas. Destacam-se as empresas que contribuem com o seu conhecimento tecnológico de base: empresas de biotecnologia com experiência anterior em outras indústrias, como a farmacêutica, ou criadas diretamente para atuar em bioenergia ao lado de start ups com outras bases de conhecimento (engenharia química, química).

Identificam-se ainda, como empresas que contribuem com seu conhecimento tecnológico acumulado, algumas empresas de química/biotecnologia (Du Pont) e enzimas (Novozymes). Movimentos recentes de empresas como Monsanto (adquirindo start ups brasileiras de genética da cana) e da BASF, anunciando o interesse em encontrar parceiros para atuar também na biotecnologia aplicada à cana-de-açúcar, reforçam a diversidade dos atores atualmente envolvidos na exploração de MPR. Essas empresas contribuem ainda com conhecimentos em engenharia de processos, indispensáveis para a produção em escala industrial. Esses conhecimentos estão, com frequência, ausentes nas empresas de base tecnológica que saem das universidades e centros de pesquisa.

Algumas empresas podem ser caracterizadas pelo seu envolvimento histórico com os combustíveis fósseis: empresas de petróleo e indústria automobilística. Essas empresas, além do aporte de financiamento para os projetos de pesquisa, podem ser importantes detentores de ativos complementares estratégicos para a introdução e adoção das inovações no mercado de combustíveis líquidos. No caso das empresas de petróleo, os biocombustíveis representam igualmente uma oportunidade de diversificação em relação aos combustíveis fósseis.

Encontram-se ainda empresas ligadas ao negócio agroindustrial. Aqui aparecem as empresas tradicionais como Cargill e ADM, com história de envolvimento na agroindústria de alimentos. Essas empresas podem ser vistas também como detentoras de ativos complementares, nesse caso ligados à cadeia de produção agrícola e logística de suprimento.

Dois casos particulares merecem um comentário a parte: Shell e BP. Chama atenção a presença marcante da Shell em cinco projetos diferentes que se estruturaram ao longo dos últimos anos. São cinco plataformas diferentes, todas exploradas na forma de associação ou participação em empresas de base tecnológica. Os projetos incluem a produção de novas matérias-primas (algas), inovações de processo (bioetanol de materiais celulósicos, combustíveis líquidos como diesel pela rota termoquímica e combustíveis a partir de açúcares pela rota química) e inovações de produtos (biogasolina). A abordagem da Shell enfatiza com clareza a aposta na inovação tecnológica como base da competição em biocombustíveis, toma como foco os biocombustíveis avançados e orienta essa aposta para a exploração de diferentes plataformas tecnológicas. Na estratégia da empresa, uma ou mais plataformas poderiam se relevar vencedoras da competição tecnológica, serem escolhidas no processo de seleção e desenvolvidas como negócios em escala comercial. As demais seriam deixadas de lado. Entretanto, o processo de planejamento tecnológico na indústria tem sido dinâmico. Recentemente, a Shell modificou em parte sua posição: a empresa deixou a associação com a Choren (produção de biocombustiveis pela via termoquímica na chamada rota BTL) e, ao mesmo tempo, adquiriu uma posição como produtora importante de etanol de cana-de-açúcar fazendo uma associação com a Cosan, líder do setor no Brasil.

$\mathrm{O}$ caso da BP mostra uma abordagem estratégica diferente. A empresa, que informa ter investido cerca de US\$1,5 bi desde 2006 em biocombustíveis e bioprodutos, evidenciou sua estratégia de 
forma mais clara com os últimos movimentos realizados. BP tem como objetivo atuar de forma ativa na expansão do mercado dos biocombustíveis partindo dos combustíveis de primeira geração e caminhando, na medida do amadurecimento dos projetos, para a produção de biocombustiveis avançados e bioprodutos. A empresa atua hoje em 7 projetos diferentes que vão da produção de etanol de primeira geração à pesquisa avançada em biotecnologia: produção de etanol no Brasil (Tropical, uma joint venture BP, Santelisa e Maeda), produção de etanol a partir de trigo no Reino Unido (Vivergo, uma joint venture BP, DuPont e British Sugar), desenvolvimento de tecnologia e produção de butanol (Butamax, uma joint venture BP e DuPont), produção de etanol a partir de materiais lignocelulósicos
(Vercipia, uma joint venture BP e Verenium), produção de diesel a partir de açúcares (projeto desenvolvido por Martek, a partir de algas com apoio da BP), biotecnologia de sementes para culturas energéticas de alta produtividade (Mendel com apoio da BP) e, finalmente, a aplicação de US\$ 500 milhões, em 10 anos, para a formação do EBI, Energy Biosciences Institute, com a participação de University of California Berkeley, Lawrence Berkeley National Laboratory e University of Illinois.

Com diferenças de enfoque, as estratégias de Shell e BP traduzem bem o processo de construção da indústria baseada em matériasprimas renováveis do futuro. 